\title{
Genotypic and phenotypic analysis of 396 individuals with mutations in Sonic Hedgehog
}

\author{
Benjamin D Solomon, ${ }^{1}$ Kelly A Bear, ${ }^{1,2}$ Adrian Wyllie, ${ }^{1}$ Amelia A Keaton, ${ }^{1}$ \\ Christele Dubourg, ${ }^{3,4}$ Veronique David, ${ }^{3,4}$ Sandra Mercier, ${ }^{4,5}$ Sylvie Odent, ${ }^{4,5}$ \\ Ute Hehr, ${ }^{6,7}$ Aimee Paulussen, ${ }^{8}$ Nancy J Clegg, ${ }^{9}$ Mauricio R Delgado, ${ }^{9}$
} Sherri J Bale, ${ }^{10}$ Felicitas Lacbawan, ${ }^{11}$ Holly H Ardinger, ${ }^{12}$ Arthur S Aylsworth, ${ }^{13,14}$ Ntombenhle Louisa Bhengu, ${ }^{15}$ Stephen Braddock, ${ }^{16}$ Karen Brookhyser, $^{17}$ Barbara Burton, ${ }^{18}$ Harald Gaspar, ${ }^{19}$ Art Grix, ${ }^{17}$ Dafne Horovitz, ${ }^{20}$ Erin Kanetzke, ${ }^{16}$ Hulya Kayserili, ${ }^{21}$ Dorit Lev, ${ }^{22}$ Sarah M Nikkel, ${ }^{23}$ Mary Norton, ${ }^{24}$ Richard Roberts, ${ }^{25}$ Howard Saal, ${ }^{26}$ G B Schaefer, ${ }^{27}$ Adele Schneider, ${ }^{28}$ Erika K Smith, ${ }^{23}$ Ellen Sowry, ${ }^{29}$ M Anne Spence, ${ }^{30}$ Stavit A Shalev, ${ }^{31,32}$ Carlos E Steiner, ${ }^{33}$ Elizabeth M Thompson, ${ }^{34}$ Thomas L Winder, ${ }^{35}$ Joan Z Balog, ${ }^{1}$ Donald W Hadley, ${ }^{1}$ Nan Zhou, ${ }^{1}$ Daniel E Pineda-Alvarez, ${ }^{1}$ Erich Roessler, ${ }^{1}$ Maximilian Muenke ${ }^{1}$

\begin{abstract}
- An additional table is published online only. To view this file please visit the journal online (http://jmg.bmj.com/ content/49/7.toc)

For numbered affiliations see end of article.
\end{abstract}

\section{Correspondence to} Dr Maximilian Muenke, Medical Genetics Branch, National Human Genome Research Institute, NIH, Bethesda, MD, USA 20892:

mamuenke@mail.nih.gov

BDS and $K A B$ contributed equally to this work. The views expressed by KAB in this article are those of the author and do not necessarily reflect the official policy or position of the Department of the Army, nor the US government.

Received 26 April 2012 Revised 17 May 2012 Accepted 29 May 2012

\section{ABSTRACT}

Background Holoprosencephaly (HPE), the most common malformation of the human forebrain, may result from mutations in over 12 genes. Sonic Hedgehog $(\mathrm{SHH})$ was the first such gene discovered; mutations in SHH remain the most common cause of nonchromosomal HPE. The severity spectrum is wide, ranging from incompatibility with extrauterine life to isolated midline facial differences.

Objective To characterise genetic and clinical findings in individuals with $\mathrm{SHH}$ mutations.

Methods Through the National Institutes of Health and collaborating centres, DNA from approximately 2000 individuals with HPE spectrum disorders were analysed for SHH variations. Clinical details were examined and combined with published cases.

Results This study describes 396 individuals, representing 157 unrelated kindreds, with $S H H$ mutations; $141(36 \%)$ have not been previously reported. SHH mutations more commonly resulted in non-HPE $(64 \%)$ than frank HPE $(36 \%)$, and non-HPE was significantly more common in patients with $\mathrm{SHH}$ than in those with mutations in the other common HPE related genes $(p<0.0001$ compared to ZIC2 or $S / X 3)$. Individuals with truncating mutations were significantly more likely to have frank HPE than those with non-truncating mutations $(49 \%$ vs $35 \%$, respectively: $p=0.012$ ). While mutations were significantly more common in the $\mathrm{N}$-terminus than in the $\mathrm{C}$-terminus (including accounting for the relative size of the coding regions, $p=0.00010$ ), no specific genotype-phenotype correlations could be established regarding mutation location

Conclusions $\mathrm{SHH}$ mutations overall result in milder disease than mutations in other common HPE related genes. HPE is more frequent in individuals with truncating mutations, but clinical predictions at the individual level remain elusive.

\section{INTRODUCTION}

Holoprosencephaly (HPE), which results from failed or incomplete forebrain separation early in gestation, is the most common malformation of the human forebrain. HPE occurs in up to 1 in 250 conceptions, but in only approximately 1 in 10000 liveborn infants due to the high proportion of intrauterine lethality. ${ }^{12}$ HPE is heterogeneous, and may result from large chromosomal imbalances, teratogenic agents, be found as one feature of an identifiable syndrome, or occur in a 'non-syndromic' context due to mutations in over 12 currently identified genes ${ }^{3}$ (reviewed in Solomon et al ${ }^{4}$ ).

Of the genes associated with HPE, Sonic Hedgehog $(\mathrm{SHH})$, was the first identified. ${ }^{5}$ As with other HPE associated genes that were identified early, the involvement of $\mathrm{SHH}$ in human HPE was suggested by cytogenetic anomalies affecting chromosome 7q36, which contains the SHH locus. ${ }^{6}$ To date, mutations affecting $S H H$ remain the single most common cause of non-chromosomal, nonsyndromic HPE, accounting for approximately $12 \%$ of such cases ${ }^{7}$ (reviewed in Pineda-Alvarez et $a l^{8}$ ).

Most SHH mutations are family/individualspecific. Determining variant pathogenicity can be challenging, especially as functional assays are not available except in isolated research circumstances. Thus, assigning true 'mutation' status to a variant usually rests on the interpretation of an experienced molecular geneticist, and is based upon inheritance patterns, clinical features, and specific variant characteristics. ${ }^{7}$

As with other genes associated with non-chromosomal, non-syndromic HPE, SHH mutations result in an autosomal, dominantly inherited condition with apparently (we use the word 'apparently', as many would agree that clinicians who are highly familiar with HPE and the range of manifestations in mutation-positive individuals would recognise subtle signs of mutation status in virtually all affected 
carriers) incomplete penetrance and highly variable expressivity. ${ }^{4}$ HPE is categorised neuroanatomically by the degree of forebrain separation into alobar (the most severe type), semilobar, lobar, middle interhemispheric variant, and septopreoptic types. ${ }^{9}$ SHH mutation 'carriers' have been described as clinically unaffected by severe sequelae of disease, and are frequently referred to as having 'microform' HPE. Strictly, individuals with microform HPE should not be termed mutation carriers: they display subtle midline anomalies on physical examination, such as midface hypoplasia, hypotelorism, a flat or sharp nasal bridge, or a single maxillary central incisor, but will often not have detectable neuroanatomical anomalies or neurocognitive disturbances. ${ }^{4}$ In many families, more individuals will be affected with microform than with frank HPE. In these families, mutation status may be suspected upon the recognition of a severely affected individual. ${ }^{4}$ 10-12

Through comparisons with cohorts of patients with mutations in the known HPE associated genes, some rudimentary intergenic genotype-phenotype correlations have been suggested. These include a preponderance of microform HPE resulting from mutations in $S H H$, a specific facial phenotype in patients with ZIC2 mutations, more severe types of HPE in patients with SIX3 mutations, and an overrepresentation of renal tract anomalies in patients with mutations in $S H H$ or ZIC2. However, no intragenic genotype-phenotype correlations have been established. ${ }^{4} 111314$

In order to describe all known patients with mutations in $\mathrm{SHH}$ associated with HPE spectrum anomalies, we formed an international collaboration and collected data from the world's largest HPE related molecular diagnostic centres. We describe 396 individuals, representing 157 unrelated kindreds, with mutations in $S H H$. In addition to outlining clinical and molecular findings, we focus on attempts to predict phenotypic severity based on genotypic data.

\section{METHODS}

Patients were ascertained retrospectively through their respective institute review board approved research protocols, with appropriate consent, and through molecular laboratories (without identifying demographic data in this latter instance). Clinical details were supplied by the referring clinicians: requested items included completion of a standardised checklist, as well as materials such as a genetics consultation note, photographs, neuroimages, and other records, though the available information was highly variable. For patients identified through testing at the National Institutes of Health, sequencing was performed using previously published methodology. Published cases were obtained through a PubMed/Medline search, using the following search terms: Sonic Hedgehog, SHH, holoprosencephaly, HPE (see supplementary table 1).

For specific portions of the presented analysis, we attempted to be conservative and not analyse variants of unknown significance along with 'true' pathogenic mutations. To do this, we intentionally excluded variants of unknown significance as defined on the basis of previous studies. ${ }^{15-18}$ In addition to literature based queries describing results of functional assays and analysis, variant pathogenicity in unclear instances was further investigated through software based prediction (Polyphen2), ${ }^{19}$ such that variants of possible but unproven pathogenicity according to the published literature that were then analysed as being unlikely to be pathogenic by software based prediction were excluded from analysis.

Statistical comparisons were made using $\chi^{2}$ or Fisher's exact test, where appropriate.

\section{RESULTS}

We describe 396 individuals (from 157 independent kindreds) with mutations in $\mathrm{SHH}$ (figure 1). One hundred and forty-one $(36 \%)$ of these individuals have not been previously reported in the medical literature. Reports in the medical literature were ascertained from 1988 through the present (some early reported individuals were later found to have $\mathrm{SHH}$ mutations). The clinical features observed in these individuals comprise the entire phenotypic spectrum, from neuroanatomical anomalies incompatible with extrauterine life to isolated, extremely subtle
Figure 1 Photographs of individuals with $\mathrm{SHH}$ mutations demonstrating salient features. In relatively severely affected individuals with frank neuroanatomic holoprosencephaly (HPE) (such as demonstrated by the top row of photos and the photo on the bottom left), common features include microcephaly, hypotelorism, flat nasal bridge, single nares, and premaxillary agenesis/cleft lip/palate. Less severely affected individuals, such as the individuals in the bottom row (middle and right), who both have microform HPE, show features such as hypotelorism and single maxillary central incisor. Top row from left: infant with semilobar HPE; infant with frank HPE (type unknown); child with HPE (type unknown). Bottom row from left: infant with lobar HPE; mother; and child in same family.
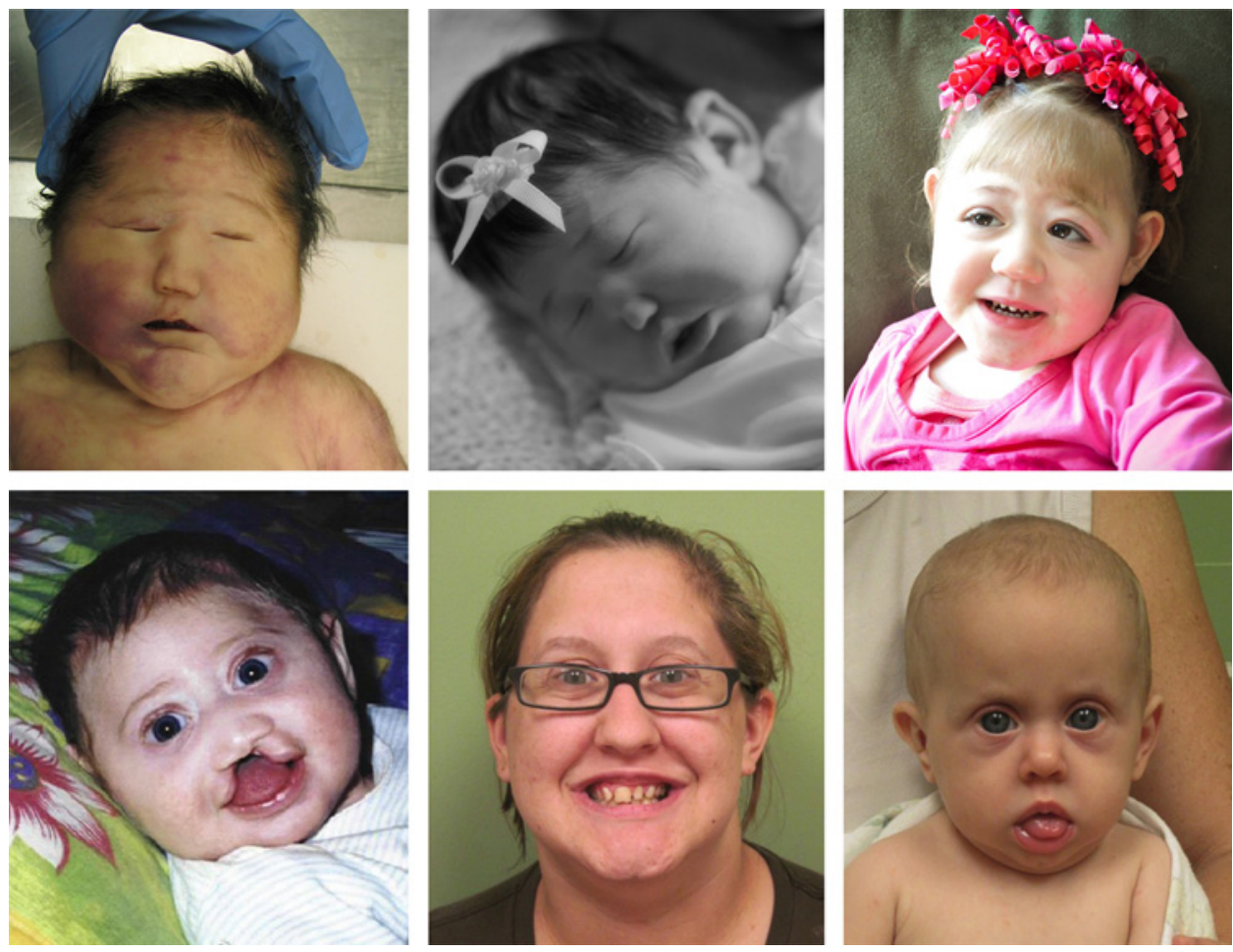
midline facial anomalies and reports of individuals who were described to be clinically 'unaffected'. Full data are available in supplementary table 1 .

There was not a statistically significant gender disproportion in probands or total individuals. Of the 396 total individuals, gender was known in 359: of the 396, 185 (47\%) were male and 174 (44\%) were female, while 37 (9\%) were of unknown gender. One hundred and thirty-four of the 157 probands had known gender: 71 (45\%) were male and 63 (40\%) were female; $23(15 \%)$ of 157 probands were of unknown gender. Of relatives of probands, 225/239 (94\%) had known gender: 114 males (48\%) and 111 females (46\%), while $14(6 \%)$ had unknown gender. The higher proportion of unknown proband gender largely results from an overrepresentation of severe HPE in probands compared to relatives (eg, due to a pregnancy loss with unknown fetal gender).

Of kindreds with a molecularly identified mutation in the proband, 98/157 (62\%) had multiple affected relatives; however, familial testing was not always available. Of the 250 mutation carriers for whom inheritance was known, 138 (55\%) had maternal inheritance, 80 (32\%) had paternal inheritance, 25 $(10 \%)$ of mutations were de novo, and 7 (3\%) (including individuals from two different families) were identified as having germline mosaicism (most likely), as neither parent was found to have the mutation on peripheral blood testing, and paternity testing confirmed parentage. The high proportion of maternally inherited mutations may be secondary to increased maternal testing, though a more specific calculation regarding this is not possible, as details regarding which parents were tested are not uniformly available.

\section{MUTATIONS}

Among the 157 families, 141 unique SHH mutations were identified (figure 2). The largest proportion of variants $(92 / 141$,
$66 \%$ ) were missense, though $17 / 92$ missense variants were considered to be variants of unknown significance (see Methods). Other mutation types included nonsense (21/141, $15 \%)$, frameshift $(17 / 141,12 \%)$, in-frame deletions or insertions (9/141, 6\%), though $2 / 9$ of these in-frame deletion/insertion variants were considered to be variants of unknown significance, and splice site mutations (2/141, 1\%).

Of the 157 families, 14 different variants were each found in two apparently unrelated kindreds, and one mutation was found in three apparently unrelated kindreds. Of these non-unique mutations, three were nonsense mutations and four were missense mutations in the SHH-N domain, and two were nonsense and six were missense mutations in the SHH-C domain.

One proband had two variants in SHH (c.327C $\rightarrow \mathrm{T}$ and c. $328 \mathrm{G} \rightarrow \mathrm{A}$ ), but the phase is unknown. Two probands had additional variants in $G A S 1,{ }^{20} 21$ one had an additional variant in $Z \mathrm{CC}_{2}{ }^{22}$ one had an additional variant in SIX3, and one had an additional variant in GGIF. $^{22}$ The pathogenicity status of these non-SHH variants is not known, however, and it is entirely possible that these simply represent rare, non-pathogenic alleles.

In order to conduct a conservative analysis, after excluding possible variants of unknown significance (see Methods) 357 individuals with variants remained, comprising 123 unique variants. Of those variants, 73 variants occurred in the $\mathrm{N}$ terminus and 50 in the C-terminus; there was a statistically significant difference in that mutations were more common in the $\mathrm{N}$-terminus when compared to the expected ratio according to the number of bases in each region $\left(\chi^{2}=14.69, p=0.00010\right)$. These differences remained significant when considering each specific type of mutation individually: single nucleotide substitutions, including those predicted to result in missense and nonsense mutations $\left(\chi^{2}=8.46, p=0.0036\right)$ and frameshift substitutions $\left(\chi^{2}=11.90, \mathrm{p}=0.00060\right)$.
Figure 2 (A) Distribution and types of variants, as well as severity of clinical manifestations are shown with the $\mathrm{SHH}$ predicted protein. (B) Individuals with frank HPE are shown below the predicted protein (with closed symbols), while individuals without evidence for neuroanatomical anomalies are shown above the predicted protein. As the figure illustrates, while overall trends may be analysed regarding genotype-phenotype correlations, individual level predictions remain elusive. HPE, holoprosencephaly; $\mathrm{SHH}$ Sonic Hedgehog.
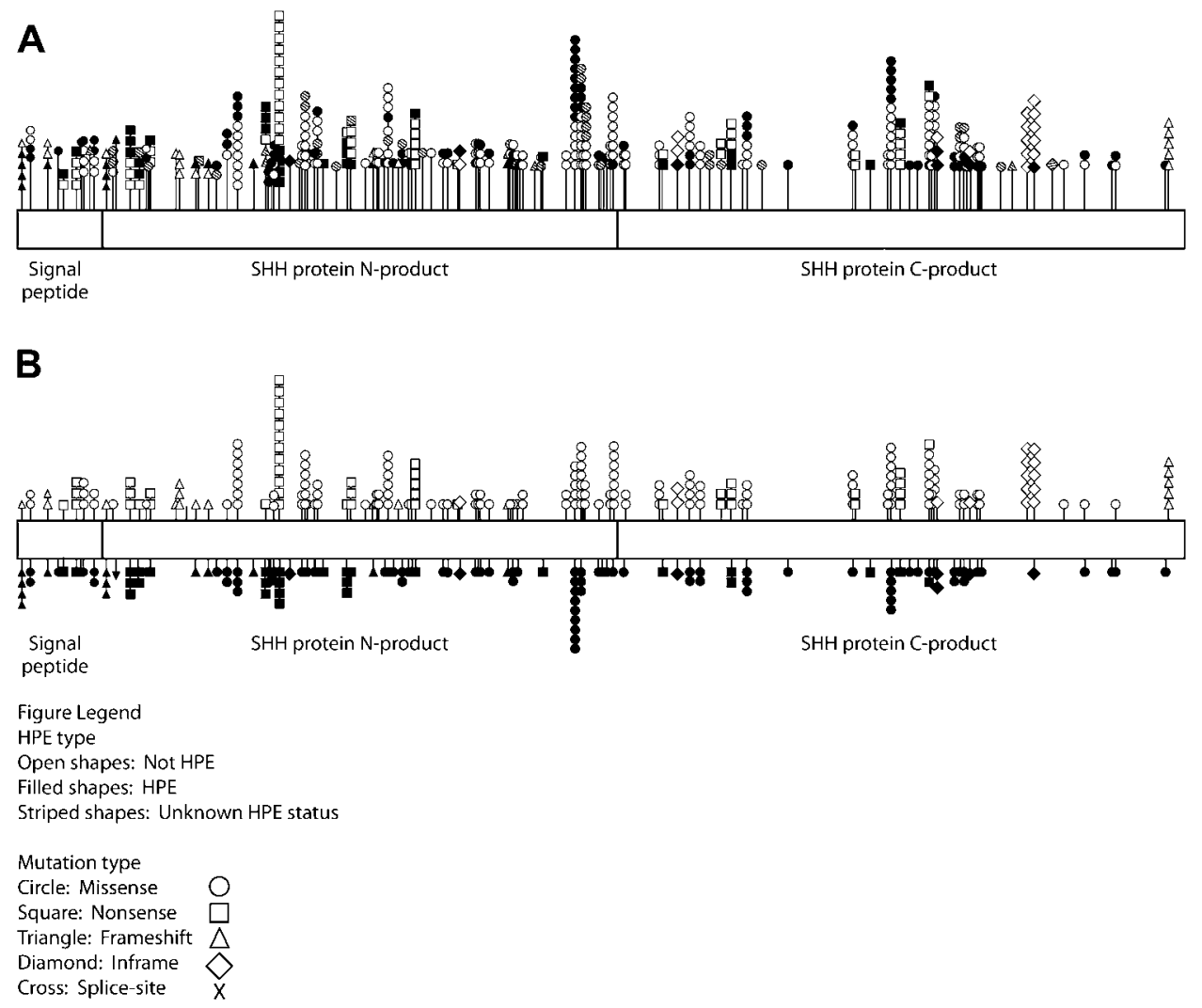


\section{CLINICAL FEATURES}

Of the 157 probands, 83 (53\%) had frank HPE. Of the probands, 27 (17\%) had alobar, 36 (22\%) had semilobar, 8 (5\%) had lobar, and 12 (8\%) had unknown type of HPE. Forty-four of 157 (28\%) did not have HPE (were considered to be microform, or not HPE unknown) and 30 (19\%) of them were unknown in terms of HPE affectedness. Of the relatives of probands, 49/239 (21\%) had frank HPE. Of the relatives of probands, $15(6 \%)$ had alobar, $5(2 \%)$ had semilobar, 3 (1\%) had lobar, and $26(11 \%)$ had unknown type of HPE, and 174/239 (73\%) did not have HPE (were categorised as 'unaffected' or microform). Sixteen (7\%) of the mutation positive relatives were unknown with respect to HPE affectedness. Table 1 shows the distribution of the types of HPE among all individuals with frank HPE. Table 2 shows the classification of HPE type among all individuals with mutations (probands and relatives).

Individuals with frank HPE were universally severely cognitively impaired, and microcephaly and hypotelorism were very commonly reported in those with available data (due to lack of uniform data, we were unable to calculate specific percentages of these features). Clinical data obtained from other reports show that the most common features commented on were (of note, some of these features may be underreported due to variable clinical data) single central maxillary incisor (21\%), cleft lip and/ or palate $(20 \%)$, choanal stenosis/atresia $(7 \%)$, coloboma $(5 \%)$, reported diabetes insipidus (DI) (3\%), reported pituitary dysfunction (in addition to DI) (3\%), proboscis (2\%), cyclopia or synophthalmia (2\%), and ptosis (1\%). Additionally, 5\% had genitourinary/renal abnormalities including hypoplastic penis, cryptorchidism, renal hypoplasia, hypospadias, and ambiguous genitalia. Two percent had cardiac abnormalities (including persistently patent ductus arteriosus, ventricular septal defect, atrial septal defect, tricuspid atresia, interrupted inferior vena cava, and situs ambiguous). Renal anomalies and cardiac defects are not considered to be a classic component of non-chromosomal, non-syndromic HPE spectrum, although a recent large case series described renal anomalies in several individuals with SHH mutations. ${ }^{14}$

\section{GENOTYPE-PHENOTYPE ANALYSIS}

Many kindreds displayed wide intrafamilial phenotypic variability. After excluding variants of unknown significance, we compared the phenotypic severity in patients with truncating mutations to those with missense or in-frame small deletions/ insertions, with the hypothesis that, despite limitations due to overgeneralisation, truncating mutations cause more severe phenotypes than hypomorphic alleles resulting from missense or in-frame mutations. Of the truncating mutations with known phenotype, 63 (49\%) individuals had frank HPE and 65 (51\%) did not have frank HPE. Of the non-truncating missense or small in-frame deletions/insertions in individuals with known

Table 1 Distribution of holoprosencephaly (HPE) types among individuals with frank HPE

\begin{tabular}{lcl}
\hline HPE type & $\begin{array}{l}\text { Probands with SHH } \\
\text { mutation, n (\%) }\end{array}$ & $\begin{array}{l}\text { Individuals with SHH } \\
\text { mutations, n (\%) }\end{array}$ \\
\hline Alobar & $27(33 \%)$ & $42(32 \%)$ \\
Semilobar & $36(43 \%)$ & $41(31 \%)$ \\
Lobar & $8(10 \%)$ & $11(8 \%)$ \\
HPE (type unknown)* & $12(14 \%)$ & $38(29 \%)$ \\
Total & 83 & 132
\end{tabular}

*HPE (type unknown): individuals identified with true HPE, which was not further categorised into specific type.
Table 2 Distribution of holoprosencephaly (HPE) among all individuals

\begin{tabular}{lcc}
\hline HPE type & $\begin{array}{l}\text { Probands with } \mathbf{S H H} \\
\text { mutation, } \mathbf{n}(\%)\end{array}$ & $\begin{array}{l}\text { Individuals with } \mathbf{S H H} \\
\text { mutation, n (\%) }\end{array}$ \\
\hline Alobar & $27(17 \%)$ & $42(11 \%)$ \\
Semilobar & $36(23 \%)$ & $41(10 \%)$ \\
Lobar & $8(5 \%)$ & $11(3 \%)$ \\
HPE (type unknown) & $12(8 \%)$ & $38(10 \%)$ \\
Microform & $42(27 \%)$ & $167(42 \%)$ \\
None & $0(0 \%)$ & $29(7 \%)$ \\
Not HPE (type unknown) $\dagger$ & $2(1 \%)$ & $22(5 \%)$ \\
Unknown (no data) $\neq$ & $30(19 \%)$ & $46(12 \%)$ \\
Total & 157 & 396 \\
\hline
\end{tabular}

*HPE (type unknown): individuals identified with true HPE, which was not further categorised into specific type.

†Not HPE (type unknown): individuals identified without HPE but not further described. łUnknown (no data): individuals without any clinical data available.

phenotype, 74 (35\%) had HPE and 138 (65\%) did not have HPE. There was a statistically significant difference such that individuals with truncating mutations had HPE more frequently than individuals with non-truncating mutations $(p=0.012$ by two-tailed Fisher's exact test).

To evaluate the potential correlation between mutation location and phenotypic severity, we analysed missense and in-frame deletions/insertions (truncating mutations were not included secondary to the possibility of nonsense mediated decay). Thirty-four individuals with HPE and 53 without HPE had Nterminus mutations. Forty individuals with HPE and 85 without HPE had C-terminus mutations. There was not a statistically significant difference ( $p=0.31$ by two-tailed Fisher's exact test) between the groups with respect to severity of phenotype and mutation location.

We compared the prevalence of HPE (117) versus non-HPE (204) in patients with SHH mutations with previously published cohorts of patients with intragenic mutations affecting the other most common HPE associated genes (ZIC2: $88 \mathrm{HPE}, 13$ non-HPE; SIX3: 59 HPE, 33 non-HPE; and TGIF: 6 HPE, 7 non-HPE). ${ }^{11} 1323$ After correcting for multiple comparisons, there was a statistically significant overrepresentation of non-HPE in the SHH cohort versus the SIX3 and ZIC2 cohorts $(p<0.0001$ for each comparison by two-tailed Fisher's exact test), while there was not a statistically significant difference compared to the TGIF cohort ( $p>0.5$ by two-tailed Fisher's exact test, likely related at least in part to a very small comparison cohort).

\section{DISCUSSION}

We present a large cohort of patients with $S H H$ mutations. To our knowledge, this is the largest described cohort with mutations in a single HPE gene. As mutations in this gene were the first and most commonly associated with HPE, SHH mutations are often considered to result in 'prototypical' HPE. ${ }^{24}$ Indeed, many of the findings described here reinforce this, including the presence of large families with multiple affected members of varying severity, as well as de novo mutations in a minority of cases, which is overall similar to the pattern seen in mutations in SIX $3,{ }^{11}$ but very different to that due to ZIC2 mutations. ${ }^{13}$ Despite the establishment of $\mathrm{SHH}$ as being associated with HPE over 15 years ago, there is still no firm explanation for the widely variable expressivity observed in these families, though plausible explanations typically involve multiple interacting genetic and environmental factors superimposed on a severely deleterious mutation. In virtually every case in which multiple mutations were purported, only one of the variants ultimately had any 
Table 3 Families with a relatively large number of severely affected individuals

\begin{tabular}{|c|c|c|c|c|c|}
\hline Mutation & Amino acid change & Type of mutation & Location & Individuals with HPE & Individuals without HPE \\
\hline c.9_12dup4 & p.Arg6GlyfsX59 & Frameshift & $\mathrm{N}$ terminus & 4 alobar & 1 microform \\
\hline c. $136 \mathrm{C} \rightarrow \mathrm{T}$ & p.Gln46X & Nonsense & $\mathrm{N}$ terminus & 1 semilobar; 2 HPE type unknown & 2 microform \\
\hline c. $383 \mathrm{G} \rightarrow \mathrm{A}$ & p.Trp128X & Nonsense & $\mathrm{N}$ terminus & 3 alobar & 1 microform \\
\hline c. $664 \mathrm{G} \rightarrow \mathrm{A}$ & p.Asp222Asn & Missense & C terminus & 2 semilobar; 7 HPE type unknown & 3 microform; 1 none; 1 not HPE unknown \\
\hline
\end{tabular}

HPE, holoprosencephaly.

evidence for pathogenicity, and thus may represent 'red herrings, ${ }^{14} 25$ (reviewed in Wannasilp et $a^{26}$ ). In fact, recent statistical evidence bears out the observation that the presence of multiple modifiers of individually small effect offers a better model of causality rather than a few digenic mutations of major effect. $^{27}$

We found that there is a significantly higher proportion of HPE in individuals with a truncating mutation versus a nontruncating mutation. This is clearly a very inexact comparison, as some missense mutations will certainly be highly functionally significant, but the overall trend is informative. ${ }^{11}$ Further functional studies may help determine the relative activity of these variants in order to perform correlations with our phenotypic data.

Interestingly, in our cohort, we have identified some families with a relatively large number of severely affected individuals, as well as other families in which many members are only mildly affected (tables 3 and 4).

Specifically, four families have high proportions of members who are severely affected. They have varying mutations: c.9_12dup4, p.Arg6GlyfsX59; c.136 C $\rightarrow$ T, p.Gln46X; c.3836 $\rightarrow$ A, p.Trp128X; c.664G $\rightarrow$ A, p.Asp222Asn. In six families, there appears to be an overrepresentation of individuals with microform HPE or who were classified as 'unaffected', again with a variety of mutation types: c.263A $\rightarrow \mathrm{T}$, p.Asp88Val; c.313A $\rightarrow$ T, p.Lys105X; c.708C $\rightarrow$ A, p.Ser236Arg; c.1051C $\rightarrow$ T, p.Gln351X; c.1202_1225del24, p.Gly404_Gly411del; c.1370delT, p.Met457ArgfsX18.

On a mutation per base level, we found that there are statistically significantly more mutations in the $\mathrm{N}$-terminus of the gene compared to the C-terminus. Specifically, there are significantly more total mutations, more substitution mutations (missense and nonsense), and more frameshift mutations. The explanation for this is unclear. For example, it could be postulated that $\mathrm{N}$-terminus mutations confer a more severe phenotype and that individuals with mutations in the C-terminus may go undiagnosed more frequently. This cannot be the only explanation, as there are individuals with severe phenotypes who have mutations in the $3^{\prime}$ end of the gene. Again, the importance of functional studies arises here in order to compare the pathogenicity of variants in the C-terminus and the impact of those variants on processing. In addition, we note that the available clinical data are not uniform, which could affect the results.

We found no difference in HPE severity based on mutation location when comparing $\mathrm{N}$-terminus to $\mathrm{C}$-terminus mutations. However, there again was a significant difference when examining the location of the types of mutations, with significantly fewer truncating mutations in the C-terminus. It is unclear why there are fewer truncating mutations in the C-terminus compared to non-truncating mutations.

As mentioned, the major limitation to this study hinges on a lack of uniform clinical and functional data, which is unfortunately inevitable, as these cases were collected over the course of more than two decades from laboratories and clinics from a number of different countries, as well as from numerous previously published reports. However, the advantage of a large cohort helps ameliorate some of these shortcomings, and allows important observations that may be helpful for clinicians and diagnostic laboratories involved with the care of affected patients. We can conclude that non-HPE is overall more common than frank HPE in individuals with $\mathrm{SHH}$ mutations. Further, compared to cohorts of patients with mutations in the other two most common HPE associated genes, mutations in SHH more frequently result in non-HPE compared to frank HPE. Individuals with truncating mutations are more likely to have frank HPE than those with non-truncating mutations. Importantly, however, within any specific family or for any single person (eg, as applies to a mutation positive fetus, which is a frequently encountered clinical question), a prediction of individual severity is not currently possible. While extra-neuroanatomical/related facial anomalies are rare, cardiac and genitourinary anomalies are found in a small percentage of patients, including those without frank HPE. The majority of mutations in $\mathrm{SHH}$ occur in the $\mathrm{N}$-terminus compared to the C-terminus and specifically that there is a paucity of truncating mutations in the C-terminus.

In summary, despite the lack of firm answers regarding major questions related to the clinical expression of $\mathrm{SHH}$ mutations, the information presented here should prove valuable to both the clinician and researcher for the purposes of helping frame questions about the pathogenicity of newly discovered variants, as well as counselling affected patients and families.

Table 4 Families with a large number of mildly affected individuals

\begin{tabular}{|c|c|c|c|c|c|}
\hline Mutation & Amino acid change & Type of mutation & Location & Individuals with HPE & Individuals without HPE \\
\hline c. $263 \mathrm{~A} \rightarrow \mathrm{T}$ & p.Asp88Val & Missense & $\mathrm{N}$-terminus & 1 alobar; 1 HPE type unknown & 6 microform \\
\hline c. $313 \mathrm{~A} \rightarrow \mathrm{T}$ & p.Lys105X & Nonsense & $\mathrm{N}$-terminus & $\begin{array}{l}1 \text { alobar; } 1 \text { semilobar; } \\
2 \text { HPE type unknown }\end{array}$ & 12 microform \\
\hline c. $708 \mathrm{C} \rightarrow \mathrm{A}$ & p.Ser236Arg & Missense & C-terminus & 1 semilobar & $\begin{array}{l}4 \text { microform; } 2 \text { none; } \\
1 \text { not HPE type unknown }\end{array}$ \\
\hline c. $1051 \mathrm{C} \rightarrow \mathrm{T}$ & p.Gln351X & Nonsense & C-terminus & 0 & 4 microform \\
\hline c.1202_1225del24 & p.Gly404_Gly411del & Inframe deletion & C-terminus & 0 & 2 microform; 3 none \\
\hline c.1370delT & p.Met457ArgfsX18 & Frameshift & C-terminus & 0 & 3 microform; 2 none \\
\hline
\end{tabular}

HPE, holoprosencephaly. 


\section{Author affiliations}

${ }^{1}$ Medical Genetics Branch, National Human Genome Research Institute, National Institutes of Health, Bethesda, Maryland, USA

2Department of Pediatrics, Walter Reed National Military Medical Center, Bethesda, Maryland, USA

${ }^{3} \mathrm{CHU}$ Rennes, Laboratoire de Génétique Moléculaire, Rennes, France

${ }^{4}$ CNRS, UMR 6290, Institut Génétique et Développement de Rennes, Université de

Rennes 1, UEB, IFR 140, Faculté, de Médecine, Rennes, France

${ }^{5}$ Service de genetique Clinique, CHU Hopital Sud, Rennes, France

${ }^{6}$ Center for Human Genetics, University of Regensburg, Regensburg, Germany

7 Department of Human Genetics, University of Regensburg, Regensburg, Germany

${ }^{8}$ Department of Clinical Genetics, Maastricht University Medical Center (MUMC+),

Maastricht, The Netherlands

${ }^{9}$ Texas Scottish Rite Hospital for Children, Dallas, Texas, USA

${ }^{10}$ GeneDx, Gaithersburg, Maryland, USA

${ }^{11}$ Molecular Genetics Pathology, Pathology and Laboratory Medicine Institute,

Cleveland Clinic, Cleveland, Ohio, USA

${ }^{12}$ Section of Genetics, Department of Pediatrics, Children's Mercy Hospitals and Clinics, Kansas City, Missouri, USA

${ }^{13}$ Department of Pediatrics, University of North Carolina, Chapel Hill, North Carolina, USA

${ }^{14}$ Department of Genetics, University of North Carolina, Chapel Hill, North Carolina, USA

${ }^{15}$ Department of Human Genetics Corner Hospital and De Korte, Johannesburg, South Africa

${ }^{16}$ Division of Medical Genetics, Department of Pediatrics, Saint Louis University, St. Louis, Missouri, USA

${ }^{17}$ Genetics Department, Kaiser Permanente, Sacramento, California, USA

${ }^{18}$ Department of Pediatrics, Northwestern University Feinberg School of Medicine and Division of Genetics, Birth Defects and Metabolism, Lurie Children's Hospital, Chicago, Illinois, USA

${ }^{19}$ Institute of Human Genetics, Heidelberg University, Heidelberg, Germany

${ }^{20}$ Centro de Genetica Medica, Instituto Fernandes Figueira-FIOCRUZ, Rio de Janeiro, Brazil

${ }^{21}$ Department of Medical Genetics, Istanbul Medical Faculty, Istanbul University, Istanbul, Turkey

${ }^{22}$ Institute of Medical Genetics, Wolfson Medical Center, Holon, Israel

${ }^{23}$ Department of Genetics, Children's Hospital of Eastern Ontario, Ottawa, Ontario, Canada

${ }^{24}$ Department of Obstetrics and Gynecology, Stanford University School of Medicine/Lucile and Packard Children's Hospital at Stanford University, Stanford, California, USA

${ }^{25}$ Genetics and Prenatal Diagnostic Center, Corpus Christi, Texas, USA

${ }^{26}$ Division of Human Genetics, Department of Pediatrics, Cincinnati Children's Hospital Medical Center, Cincinnati, Ohio, USA

${ }^{27}$ Division of Medical Genetics, University of Arkansas for Medical Sciences, Little Rock, Arkansas, USA

${ }^{28}$ Genetics Division, Einstein Medical Center, Philadelphia, Pennsylvania, USA

${ }^{29}$ Division of Medical Genetics, Children's Hospital of Pittsburgh, Pittsburgh, Pennsylvania, USA

${ }^{30}$ Department of Pediatrics, University of California, Irvine, California, USA

${ }^{31}$ Genetics Institute, Emek Medical Center, Afula, Israel

${ }^{32}$ Rappaport faculty of Medicine, Technion, Haifa, Israel

${ }^{33}$ Department of Medical Genetics, School of Medical Sciences, Universidade Estadual de Campinas (UNICAMP), Campinas, Sao Paulo, Brazil

${ }^{34}$ Clinical Genetics Unit, SA Pathology, Women's and Children's Hospital and University of Adelaide, Adelaide, South Australia

${ }^{35}$ Prevention Genetics, Marshfield, Wisconsin, USA

Contributors All authors contributed to the concept, design, acquisition of data or analysis and interpretation of data. All authors contributed to drafting or revising the content and approved the final version. The authors would like to express their deepest gratitude to all the patients and families who have participated in their research on holoprosencephaly and related conditions. We would like to express gratitude to Julia Fekecs and Darryl Leja for their help with illustrations and to Dr Alexia Pena Vargas, Deparment of Paediatrics, Endocrinology and Diabetes, Women's and Children's Hospital and University of Adelaide, South Australia for her referral.

Funding This work was supported by the Division of Intramural Research, National Human Genome Research Institute, National Institutes of Health, Department of Health and Human Services, USA.

Competing interests None

Patient consent Obtained.

Ethics approval Ethics approval was provided by National Human Genome Research Institute IRB.

Provenance and peer review Not commissioned; externally peer reviewed.
Data sharing statement All relevant data are included in this article. All other clinical information specific to patients is managed by their respective clinicians and/or our reference laboratories.

\section{REFERENCES}

1. Matsunaga E, Shiota K. Holoprosencephaly in human embryos: epidemiologic studies of 150 cases. Teratology 1977;16:261-72.

2. Leoncini E, Baranello G, Orioli IM, Annerén G, Bakker M, Bianchi F, Bower C, Canfield MA, Castilla EE, Cocchi G, Correa A, De Vigan C, Doray B, Feldkamp ML, Gatt M, Irgens LM, Lowry RB, Maraschini A, Mc Donnell R, Morgan M, Mutchinick O. Poetzsch S, Riley M, Ritvanen A, Gnansia ER, Scarano G, Sipek A, Tenconi R, Mastroiacovo P. Frequency of holoprosencephaly in the International Clearinghouse Birth Defects Surveillance Systems: searching for population variations. Birth Defects Res A Clin Mol Teratol 2008;82:585-91.

3. Roessler E, Muenke M. The molecular genetics of holoprosencephaly. Am J Med Genet C Semin Med Genet 2010;154C:52-61.

4. Solomon BD, Mercier S, Vélez JI, Pineda-Alvarez DE, Wyllie A, Zhou N, Dubourg C David V, Odent S, Roessler E, Muenke M. Analysis of genotype-phenotype correlations in human holoprosencephaly. Am J Med Genet C Semin Med Genet 2010;154C:133-41.

5. Roessler E, Belloni E, Gaudenz K, Jay P, Berta P, Scherer SW, Tsui LC, Muenke M. Mutations in the human Sonic Hedgehog gene cause holoprosencephaly. Nat Genet 1996;14:357-60.

6. Gurrieri F, Trask BJ, van den Engh G, Krauss CM, Schinzel A, Pettenati MJ, Schindler D, Dietz-Band J, Vergnaud G, Scherer SW, Tsui L, Muenke M. Physical mapping of the holoprosencephaly critical region on chromosome 7q36. Nat Genet 1993:3:247-51.

7. Roessler E, El-Jaick KB, Dubourg C, Vélez JI, Solomon BD, Pineda-Alvarez DE, Lacbawan F, Zhou N, Ouspenskaia M, Paulussen A, Smeets HJ, Hehr U, Bendavid C, Bale S, Odent S, David V, Muenke M. The mutational spectrum of holoprosencephaly-associated changes within the SHH gene in humans predicts lossof-function through either key structural alterations of the ligand or its altered synthesis. Hum Mutat 2009;30:E921-35.

8. Pineda-Alvarez DE, Dubourg C, David V, Roessler E, Muenke M. Current recommendations for the molecular evaluation of newly diagnosed holoprosencephaly patients. Am J Med Genet C Semin Med Genet 2010;154C:93-101.

9. Hahn JS, Barnes PD, Clegg NJ, Stashinko EE. Septopreoptic holoprosencephaly: a mild subtype associated with midline craniofacial anomalies. AJNR Am J Neuroradiol 2010:31:1596-601.

10. Hehr U, Gross C, Diebold U, Wahl D, Beudt U, Heidemann P, Hehr A, Mueller D. Wide phenotypic variability in families with holoprosencephaly and a sonic hedgehog mutation. Eur J Pediatr 2004:163:347-52.

11. Lacbawan F, Solomon BD, Roessler E, El-Jaick K, Domené S, Vélez JI, Zhou N, Hadley D, Balog JZ, Long R, Fryer A, Smith W, Omar S, McLean SD, Clarkson K, Lichty A, Clegg NJ, Delgado MR, Levey E, Stashinko E, Potocki L, Vanallen MI, Clayton-Smith J, Donnai D, Bianchi DW, Juliusson PB, Njolstad PR, Brunner HG, Carey JC, Hehr U, Müsebeck J, Wieacker PF, Postra A, Hennekam RC, van den Boogaard MJ, van Haeringen A, Paulussen A, Herbergs J, Schrander-Stumpel CT, Janecke AR, Chitayat D, Hahn J, McDonald-McGinn DM, Zackai EH, Dobyns WB, Muenke M. Clinical spectrum of SIX3-associated mutations in holoprosencephaly: correlation between genotype, phenotype and function. J Med Genet 2009:46:389-98

12. Solomon BD, Lacbawan F, Jain M, Domené S, Roessler E, Moore C, Dobyns WB Muenke M. A novel SIX3 mutation segregates with holoprosencephaly in a large family. Am J Med Genet A 2009;149A:919-25.

13. Solomon BD, Lacbawan F, Mercier S, Clegg NJ, Delgado MR, Rosenbaum K Dubourg C, David V, Olney AH, Wehner LE, Hehr U, Bale S, Paulussen A, Smeets HJ, Hardisty E, Tylki-Szymanska A, Pronicka E, Clemens M, McPherson E, Hennekam RC Hahn J, Stashinko E, Levey E, Wieczorek D, Roeder E, Schell-Apacik CC, Booth CW Thomas RL, Kenwrick S, Cummings DA, Bous SM, Keaton A, Balog JZ, Hadley D, Zhou N, Long R, Vélez JI, Pineda-Alvarez DE, Odent S, Roessler E, Muenke M. Mutations in ZIC2 in human holoprosencephaly: description of a novel ZIC2 specific phenotype and comprehensive analysis of 157 individuals. J Med Genet 2010:47:513-24.

14. Mercier S, Dubourg C, Garcelon N, Campillo-Gimenez B, Gicquel I, Belleguic $M$, Ratié $L$, Pasquier L, Loget $P$, Bendavid $C$, Jaillard S, Rochard L, Quélin C, Dupé V, David V, Odent S. New findings for phenotype-genotype correlations in a large European series of holoprosencephaly cases. J Med Genet 2011:48:752-60

15. Singh S, Tokhunts R, Baubet V, Goetz JA, Huang ZJ, Schilling NS, Black KE, MacKenzie TA, Dahmane N, Robbins DJ. Sonic hedgehog mutations identified in holoprosencephaly patients can act in a dominant negative manner. Hum Genet 2009;125:95-103.

16. Maity T, Fuse N, Beachy PA. Molecular mechanisms of Sonic hedgehog mutant effects in holoprosencephaly. Proc Natl Acad Sci U S A 2005; 102:17026-31.

17. Traiffort E, Dubourg C, Faure H, Rognan D, Odent S, Durou MR, David V, Ruat M Functional characterization of sonic hedgehog mutations associated with holoprosencephaly. J Biol Chem 2004;279:42889-97. 
18. Schell-Apacik C, Rivero M, Knepper JL, Roessler E, Muenke M, Ming JE. SONIC HEDGEHOG mutations causing human holoprosencephaly impair neural patterning activity. Hum Genet 2003;113:170-7.

19. Adzhubei IA, Schmidt S, Peshkin L, Ramensky VE, Gerasimova A, Bork P, Kondrashov AS, Sunyaev SR. A method and server for predicting damaging missense mutations. Nat Methods 2010;7:248-9.

20. Ribeiro LA, Quiezi RG, Nascimento A, Bertolacini CP, Richieri-Costa A. Holoprosencephaly and holoprosencephaly-like phenotype and GAS1 DNA sequence changes: report of four Brazilian patients. Am J Med Genet A 2010:152A:1688-94.

21. Richieri-Costa A, Ribeiro LA. Holoprosencephaly-like phenotype: clinical and genetic perspectives. Am J Med Genet A 2006;140:2587-93.

22. Nanni L, Ming JE, Bocian M, Steinhaus K, Bianchi DW, Die-Smulders C, Giannotti A, Imaizumi K, Jones KL, Campo MD, Martin RA, Meinecke P, Pierpont ME, Robin NH, Young ID, Roessler E, Muenke M. The mutational spectrum of the sonic hedgehog gene in holoprosencephaly: SHH mutations cause a significant proportion of autosomal dominant holoprosencephaly. Hum Mol Genet 1999;8:2479-88.
23. Keaton AA, Solomon BD, Kauvar EF, El-Jaick KB, Gropman AL, Zafer Y, Meck JM, Bale SJ, Grange DK, Haddad BR, Gowans GC, Clegg NJ, Delgado MR, Hahn JS, Pineda-Alvarez DE, Lacbawan F, Vélez JI, Roessler E, Muenke M. TGIF mutations in human holoprosencephaly: correlation between genotype and phenotype. $\mathrm{Mol}$ Syndromol 2010;1:211-22.

24. Cohen MM. Holoprosencephaly: clinical, anatomic, and molecular dimensions. Birth Defects Res Part A Clin Mol Teratol 2006;76:658-73.

25. Ming JE, Muenke M. Multiple hits during early embryonic development: digenic diseases and holoprosencephaly. Am J Hum Genet 2002:71:1017-32.

26. Wannasilp N, Solomon BD, Warren-Mora N, Clegg NJ, Delgado MR, Lacbawan F Hu P, Winder TL, Roessler E, Muenke M. Holoprosencephaly in a family segregating novel variants in ZIC2 and GLI2. Am J Med Genet A 2011:155A:860-4.

27. Roessler E, Vélez JI, Zhou N, Muenke M. Utilizing prospective sequence analysis of SHH, ZIC2, SIX3 and TGIF in holoprosencephaly probands to describe the parameters limiting the observed frequency of mutant geneXgene interactions. Mol Genet Metab 2012;105:658-64. 


\section{JMG}

Genotypic and phenotypic analysis of 396 individuals with mutations in Sonic Hedgehog

Benjamin D Solomon, Kelly A Bear, Adrian Wyllie, Amelia A Keaton, Christele Dubourg, Veronique David, Sandra Mercier, Sylvie Odent, Ute Hehr, Aimee Paulussen, Nancy J Clegg, Mauricio R Delgado, Sherri J Bale, Felicitas Lacbawan, Holly $\mathrm{H}$ Ardinger, Arthur S Aylsworth, Ntombenhle Louisa Bhengu, Stephen Braddock, Karen Brookhyser, Barbara Burton, Harald Gaspar, Art Grix, Dafne Horovitz, Erin Kanetzke, Hulya Kayserili, Dorit Lev, Sarah M Nikkel, Mary Norton, Richard Roberts, Howard Saal, G B Schaefer, Adele Schneider, Erika K Smith, Ellen Sowry, M Anne Spence, Stavit A Shalev, Carlos E Steiner, Elizabeth M Thompson, Thomas L Winder, Joan Z Balog, Donald W Hadley, Nan Zhou, Daniel E Pineda-Alvarez, Erich Roessler and Maximilian Muenke

J Med Genet 2012 49: 473-479

doi: 10.1136/jmedgenet-2012-101008

Updated information and services can be found at: http://jmg.bmj.com/content/49/7/473

\section{These include:}

Supplementary Supplementary material can be found at:

Material http://jmg.bmj.com/content/suppl/2012/07/11/jmedgenet-2012-101008 .DC1

References This article cites 27 articles, 6 of which you can access for free at: http://jmg.bmj.com/content/49/7/473\#BIBL

Email alerting Receive free email alerts when new articles cite this article. Sign up in the service box at the top right corner of the online article.

Topic Articles on similar topics can be found in the following collections Collections

\section{Notes}

To request permissions go to:

http://group.bmj.com/group/rights-licensing/permissions

To order reprints go to:

http://journals.bmj.com/cgi/reprintform

To subscribe to BMJ go to:

http://group.bmj.com/subscribe/ 